\title{
Monetary Response to Exchange Rate Dynamics: Regime Switching - Chartists and Fundamentalists Application to Australia
}

\author{
Ph.D. Candidate Ferry Syarifuddin (Bank Indonesia, Indonesia)
}

\begin{abstract}
In this paper we study the effect of central bank intervention within a heterogeneous expectations exchange rate model. The empirical evidence is conducted by applying a Markov switching approach to daily AUD/USD exchange rate, intervention data of the Reserve Bank of Australia from 2006 to 2012. Our results are supporting both chartists and fundamentalist regimes. It is shown that the two regimes are persistent. However, Reserve Bank of Australia efforts to exert a stabilizing effect of foreign exhange interventions, the result is inconclusive.
\end{abstract}

\section{Introduction}

According with the postulate trilemna, freely floating exchange rate will be adapted by a country which adapts freely foreign exchange system and independent monetary policy. Australia is one of the country that adapts it. By freely floating exchange rate and position as an advanced open economy, Australia's exchange rate movements is strongly influenced by capital flows. Hence, existence of central bank optimal monetary response (i.e.foreign exchange intervention) needed to control the exchange rate for the long-term equilibrium exchange rate.

An intervention (non-sterilized) occurs when a monetary authority buys (sells) foreign exchange. This action will affect the monetary base, interest rates, market expectations and intimately the exchange rate. Intervention is said sterilized if the monetary authority offsets or sterilizes the effect of the foreign exchange operation on the monetary base by selling or buying domestic bonds in order to keep the monetary policy unchanged. The main results in the empirical literature (Almekinders et al., 1996; Frenkel et al., 2004; Ito and Yabu, 2007; Jun, 2008 and in papers of surveys Neely, 2001) suggest that interventions tend to be conducted in order to reduce exchange rate misalignment or to reduce foreign exchange undesired fluctuations.

Relying on the efforts of monetary authorities to maintain exchange rate stability, economic actors usually are actively hedging the exchange rate in order to avoid losses due to exchange rate fluctuations. Rothig, Semmler, and Flaschel (2005) argued that the negative effect of exchange rate on the balance sheet can be removed by the practice of company risk management. Risk management of exchange rate fluctuations will be conducted by hedging. Hedging generally conducts by forward transactions, swaps, NDF etc.

The effectiveness of sterilized interventions was usually evaluated on the basis of traditional macro-economic channels: the portfolio balance channel and the signaling channel. With the emergence of microstructure approach of exchange rate (Lyons, 2006) and the failure of numerous empirical studies (based on the asset market approach of exchange rate) to explain short term movements of exchange rate (Lewis, 1995 and Taylor, 1995) many other studies have used to introduce microstructure based channels and microstructure variables. These studies suggested two new channels through which sterilized intervention may be transmitted: the noise trading channel (Hung, 1997) and the coordination channel (Reitz and Taylor, 2008, Taylor, 2004, 2005). Microstructure specification like order flow, Bid-ask spread, market makers, heterogeneity of traders, was also taken into account for studying the effectiveness of intervention (Beine et al., 2009, Chari, 2007, Scalia, 2008).

The noise trading channel have been pioneered by Hung (1997) and is based on the functioning and the microstructure of the foreign exchange market. This channel assumes two hypotheses: noise traders must prevail the foreign exchange market and the exchange rate is determined by flow market equilibrium. Once these hypotheses are satisfied, the central bank should intervene in highly volatile market periods and keep its interventions secret.

This study contributes to the noise trading channel by allowing intervention to influence the both forecasting rules of chartists and fundamentalists, thereby altering the proportion of the two groups in the foreign exchange market. We define a new criterion for the effectiveness of interventions. To allow for different forecasting strategies, the impact of central bank intervention is investigated applying a heterogeneous expectations exchange rate model. A central bank intervening in the foreign exchange market is considered effective if the exchange rate is driving closer to its fundamental value. Apart from providing the rationale for the application of trading rules, intervention may as well improve the performance of expectations based on fundamentals, especially when central banks try to correct current exchange rate misalignments.

Following Frankel \&Froot (1986), the excess demand for foreign currency is assumed to be a function of the relative success of chartist and fundamentalist forecasting techniques. As is stated above the performance of 
chartist or fundamentalist predictions is expected to be temporarily improved by central bank intervention thereby altering the time series properties of exchange rates.

This article presents a new and improved data series on interventions by RBA in the foreign exchange market. These data allow a documentation of the evolution in the approach to foreign exchange market intervention after the float of the exchange rate. This evolution reflects a recognition that when foreign exchange markets are deep and liquid (and the capital account is open), the effects of intervention on the level of the exchange rate are generally short-lived. Moreover, under these 'normal' circumstances, the practical difficulties involved in determining what the 'fair value' of an exchange rate should be suggest that it is difficult for policymakers to systematically improve on market outcomes, particularly in real time. Nevertheless, in instances of severe market dysfunction, intervention can exert an important stabilising influence on the foreign exchange market.

The article uses the new data to reassess previous empirical assessments of the effectiveness of foreign exchange market intervention. It shows that it is not possible to draw strong conclusions, notwithstanding the use of an improved measure of RBA interventions. The well-known limitations of this type of analysis suggest that the estimates of the effect of intervention on the exchange rate are expected to be understated, and may even be perverse. Moreover, as the goal of intervention has evolved toward addressing instances of extreme market dysfunction, it has become less clear that such specifications are still well-suited for assessing the effectiveness of foreign exchange market intervention.

The empirical examination of the hypothesis is done by applying the Markov regime-switching approach originally proposed by Hamilton (1989) to daily RBA intervention data from 2006 to 2012. Considering the results of Neely and Weller (2001) intervention data is used only to construct a dummy variable distinguishing between intervention and no-intervention periods. Statistically significant estimates of dummy coefficients lead to the conclusion that an impact of central bank intervention on exchange rate expectation cannot be rejected.

Furthermore, we re-examine the effects of intervention on exchange rate volatility, where empirical work has reported quite mixed results. The parameter estimates of the Markov switching model suggest that the inconclusive evidence is due to a regime dependent correlation between the intervention and volatility. Dominguez (1998) estimates $\operatorname{GARCH}(1,1)$ models and shows that overt intervention was able to reduce volatility in certain periods. But in general, intervention seemed to have an increasing effect on the conditional variance of exchange rate changes (Baillie and Osterberg, 1997b).

The remainder of the paper is organized as follow. Section 2 describes the problem formulation, followed by Research Objectives in section3. Research methodology is presented in section 4. Section 5 describe literature and Theoretical Background. Then in section 6 we explain the econometric model used. Our main empirical results concerning intervention effectiveness are reported in Section 7 before the final section (8) concludes.

\section{Problem Formulation}

How to get a model that could explain exchange rate dynamics built by FX traders (fundamentalist and chartist) as well as the relationship between changes in exchange rateand foreign exchange intervention (monetary policy)? How to estimate the volatility of the exchange rate using by the model?

\section{Research Objectives}

These paper objectives are as follow:

- To get a model that could explain exchange rate dynamics built by FX traders (fundamentalist and chartist) in the case of Australia

- To expand the model that could explain the relationship between changes in exchange rate, and foreign exchange intervention (monetary policy)?

- To estimate the volatility of the exchange rate using the model?

\section{Research Methodology}

This study contributes to the noise trading channel by allowing intervention to influence the exchange rate both forecasting rules of chartists and fundamentalists, thereby altering the proportion of the two groups in the foreign exchange market. We define a new criterion for the effectiveness of interventions. A central bank intervening in the foreign exchange market is considered effective if the exchange rate is driving closer to its fundamental value. The models are estimated by maximum likelihood. Estimated parameters obtained by using the BFGS algorithm (Broyden-Fletcher-Goldfarb-Shanno), a method of solving nonlinear optimization problems, and t-statistics which reported by the heteroscedasticity-consistent standard errors based (White, 1982). For data processing, the software used is RATS 6.0 


\section{Literature and Theoretical Background}

In the literature of financial markets, participants are classified in two groups according to different approaches of expectations; the fundamental analysis and the chartist analysis. The classification was introduced by Frankel and Froot (1986, 1990), and has been enhanced among others by Ahrens and Reitz (2004), Reitz (2005), Westerhoff (2003), De Grauwe and Grimaldi (2005), Wieland and Westerhoff (2005).

Beine et al. (2009) investigated the effect of sterilized intervention in a noise trading channel with two states Markov switching model. Using biweekly data, they found that interventions increase the weight of fundamentalists in the foreign exchange market and therefore exert stabilizing influence on the exchange rate. The fundamentalists behavior tends to stabilize the market while the presence of chartists may cause destabilization.

There are many economists are interested to see the effectiveness of exchange rate intervention which conducted by central bank due to stabilize the exchange rate. However, there are also the differences about the view of exchange rate intervention affectivity to stabilize the exchange rate. Taylor (2004) examines the effectiveness of exchange rate intervention by using Markov switching model for the real exchange rates. The probability of switching between stable and unstable regimes depends nonlinearly upon the amount of intervention, the degree of misalignment and the duration of the regime. Taylor applied this to dollar-mark data for the period 1985-98. Markov switching models can have also been used recently to study the effectiveness of intervention (Taylor 2004). In conclusion, Taylor shows that the intervention increase the probability of stability when the rate is misaligned, and that its influence grows with the degree of misalignment. However, intervention within a small neighborhood of equilibrium will result in a greater probability of instability.

Dominguez (1998) tried to analyze whether intervention operations generally increase exchange rate volatility. Dominguez explored the effect of foreign exchange intervention by the G-3 central banks (US, German, and Japanese) on the behavior of exchange rates over the 1977-1994 period. The G-3 central banks have undertaken an unprecedented number of both coordinated and unilateral intervention operations in the last 10 years.

Existing empirical evidence on the effectiveness of intervention is mixed. Dominguez examines the effect of US, German, and Japanese monetary and foreign exchange intervention on dollar-mark and dollar-yen exchange rate volatility over the 1977-1994 period. The results indicate that intervention operations generally increase exchange rate volatility. Besides the effectiveness, economists are also interested to analyze the expectations from the businesses on the exchange rate movements after the existing of exchange intervention by central bank. Cited by Messe (1990) from Vigfusson (1996), models based on economic fundamentals have been poor at explaining the movements in the exchange rate since the early 1980s.

The effectiveness of sterilized interventions was usually evaluated on the basis of traditional macro economic channels:

- The portfolio balance channel

- The signaling channel

With the emergence of microstructure approach of exchange rate (Lyons, 2006) and the failure of numerous empirical studies to explain short term movements of exchange rate (Lewis, 1995 and Taylor, 1995) many other studies have used to introduce microstructure based channels and microstructure variables. These microstructure approach of exchange rate studies suggested two new channels through which sterilized intervention may be transmitted. The noise trading channel (Hung, 1997) is based on the functioning and the microstructure of the foreign exchange market. This channel assumes two hypotheses: noise traders must prevail the foreign exchange market and the exchange rate is determined by flow market equilibrium. Microstructure specification like order flow, Bid-ask spread, market makers, heterogeneity of traders, was also taken into account for studying the effectiveness of intervention (Beine et al., 2009, Chari, 2007, Scalia, 2008).

For example, the high appreciation of dollar (US) in the beginning of 1980-an have been poor at explaining by the fundamental perspective. In response to this problem, Frankel and Froot (1988) developed a model where two approaches are used to forecast the exchange rate, chartist and fundamentalists $(\mathrm{C} \& \mathrm{~F})$. The fundamentalist approach, where the forecast is based upon economic fundamentals, continues to be used. This models innovation is that the chartist approach, where the forecast is based upon the past behavior of the exchange rate, is also used.

Although the model C\&F looks well-satisfied, there's still no direct empirical test. The main problem lies on the relative importance of each market players which has various kind and unobservable. This condition makes the difficultly to estimate this model with the general statistical methods. Vigfusson (1996) tried to solve this problem by using the Markov regime-switching model. Markov switching model explains the C\&F model within two concerns. First, $C \& F$ model has two forecasting equations of both chartist and fundamentalist. Second, $C \& F$ model placed the time-varying weight on each forecasting equations. Vigfusson explains about the response of the financial market players to influence the exchange rates expectation by observe the switching contribution between chartist and fundamentalist. By defining the two groups different methods of forecasting as regimes, 
Vigfusson rewrite the C\&F model as a regime-switching model. This approach is used to test for chartist and fundamentalist behavior in the Canada-US daily exchange rate between 1983 and 1992. Vigfusson found favorable though inconclusive evidence for the $C \& F$ model because the difference of regime variance assessed more important than the other variables. Ideally, this model could aside the switching that caused by the differences of variance and made both of the regime used the ARCH effect. Therefore, he suggest to do the further research.

The further research from Reitz (2002) is about the usage of C\&F model to analyze the exchange rate behavior which connected to the foreign exchange intervention by central bank. Reitz propose a generalization of the noise trader transmission mechanism to examine the impact of central bank intervention on exchange rates. Within a heterogeneous expectations exchange rate model intervention operations are supposed to provide support to either chartist or fundamentalist forecasts, which forces portfolio managers to adjust their foreign currency positions.

The empirical examination of the hypothesis is done by applying a Markov regime-switching approach to daily US-dollar/DEM forward rates and intervention data of the Deutsche Bundesbank and the Federal Reserve from 1979 to 1992. It is shown that the performance of simple chartist trading rules was strong whenever these central banks intervened on the foreign exchange market. Instead, the fundamentalists which used the fundamentalist technique has a worse estimation results.

Jonathan Kearns and Roberto Rigobon (2003) argued that the endogeneity of exchange rates and intervention has long plagued studies of the effectiveness of central banks' actions in foreign exchange markets. Researchers have either excluded contemporaneous intervention so that their explanators are predetermined, or obtained a small, and typically incorrectly signed, coefficient on contemporaneous intervention. Failing to account for the endogeneity, when central banks lean against the wind and trade strategically, will likely result in a large downward bias to the coefficient on contemporaneous intervention - explaining the negative coefficient frequently obtained.

The RBA researchers use an alternative identification assumption - a change in the intervention policy of the Reserve Bank of Australia - that allows them to estimate, using simulated Generalised Method of Moments (GMM), a model that includes the contemporaneous impact of intervention. There are three main results. Their point estimates suggest that central bank intervention has an economically significant contemporaneous effect. A US\$100 million purchase of the domestic currency will appreciate the exchange rate by 1.3 to 1.8 per cent. This estimate is remarkably similar to the calibration conducted by Dominguez and Frankel (1993c), who themselves noted their estimate was larger than previous empirical findings. Secondly, the vast majority of the effect of an intervention on the exchange rate is found to occur during the day in which it is conducted, with only a smaller impact on subsequent days. Finally, they confirm findings that Australian central bank intervention policy can be characterized as leaning against the wind.

The Reserve Bank's approach to foreign exchange market intervention has evolved since the float of the Australian dollar in 1983, as the Australian foreign exchange market has developed and market participants have become better equipped to manage their foreign exchange risk. Over time, foreign exchange market intervention has become much less frequent and more targeted towards addressing periods of market dysfunction. This article presents a new dataset and summarises the key characteristics of major intervention episodes since the late 2000s. Some simple regression analysis is undertaken to gauge the effectiveness of these interventions, but the results mainly illustrate the inherent limitations of such exercises.

\section{The Econometric Model}

In the literature of financial markets, participants are classified in two groups according to different approaches of expectations; the fundamental analysis and the chartist analysis. The classification was introduced by Frankel and Froot (1986, 1990), and has been enhanced among others by Ahrens and Reitz (2004), Reitz (2005), Westerhoff (2003), De Grauwe and Grimaldi (2005), Wieland and Westerhoff (2005). Beine et al. (2009) investigated the effect of sterilized intervention in a noise trading channel with two states Markov switching model. Using biweekly data, they found that interventions increase the weight of fundamentalists in the foreign exchange market and therefore exert stabilizing influence on the exchange rate. The fundamentalists behavior tends to stabilize the market while the presence of chartists may cause destabilization.

\subsection{A Basic Chartist-Fundamentalist Model for The Exchange Rate}

As discussed in the last section, we consider heterogeneous traders in our model: fundamentalists and chartists. Fundamentalists, using fundamentalist rule, base their forecasts on the fundamental exchange rate; they expect that exchange rate converge to its fundamental value. While chartists, using technical analysis rules, explore paste movements of exchange rate in the future. Fundamentalists forecasting rules and chartists forecasting rules can be expressed, respectively, as follow:

$$
r_{f, t}=-\psi\left(e_{t-1}-f_{t-1}\right)+\epsilon_{f, t}
$$




$$
r_{c, t}=C\left(r_{t i}\right)+\epsilon_{c, t} r_{c, t}=C\left(r_{t i}\right)+\epsilon_{c, t}
$$

Fundamentalists consider exchange rate as a reaction function to misalignments of exchange rate level with the fundamental value. $r_{\mathrm{f}, \mathrm{i}}$ is the forecasted value of the exchange rate return $\mathrm{r}_{\mathrm{t}}$ by fundamentalists, $-\psi \psi$ is speed of adjustment parameter , $\mathrm{ft}-1$ is the fundamental exchange rate, $\mathrm{C}_{\mathrm{f}, \mathrm{t}}$ is the error term of fundamentalists. $\mathrm{r}_{\mathrm{c}, \mathrm{t}}$ is the forecasted value of the exchange rate return $r$ by chartists, $C$ the chartists forecasting rule, $\epsilon_{c, t}$ is the error term of chartists.

In order the characterize the exchange rate behavior of exchange rate, we choose the Markov regime-switching model. It was initially introduced by Hamilton (1989) and developed further by, among others, Engel (1994) and Dewachter (1996). In Markov switching model, dynamics of the exchange rate is governed by an unobserved state variable or a latent variable $\mathrm{lt}(\mathrm{lt}=\mathrm{c}$ for chartist regime $\mathrm{lt}=\mathrm{f}$ for fundamentalists one). The indicator regime It is parametrized as a first order Markov process and is driven by first-order transition probabilities. These transitions probabilities, in the case of two regimes, could be expressed as:

$$
\begin{gathered}
p=\operatorname{prob}\left(l_{t}=f \mid l_{t-1}=f\right) \\
q=\operatorname{prob}\left(l_{t}=c \mid l_{t-1}=c\right)
\end{gathered}
$$

These probabilities are constant over time. In this specification, $p$ is the probability of remaining in the fundamentalist regime, and $\mathrm{q}$ for the chartist

$$
\begin{aligned}
& p=1-\left(1-\exp \left(\pi_{0}\right)\right)^{-1} \\
& q=1-1-\left(1-\exp \left(\kappa_{0}\right)\right)^{-1}
\end{aligned}
$$

\subsection{Model Specification}

As used by Reitz (2002), in the standard chartist and fundamentalist (C\&F) model originally suggested by Frankel and Froot (1986) the (log of the) exchange rate $\mathrm{e}_{\mathrm{t}} \widetilde{e_{t}}$ is driven by the decisions of portfolio managers. They buy and sell foreign currency in response to changes in the expected rate of appreciation and a set of contemporaneous variables included in a vector zt. Thus, the exchange rate can be written as:

$$
e_{t}=a E_{t}\left[\Delta e_{t+1}\right]+b z_{t} e_{t}=a E_{t}\left[\Delta e_{t+1}\right]+b z_{t}
$$

Where the vector of elasticities of the contemporaneous variables (b) and the elasticity of exchange rate expectation (a) should be constant overtime. Under the rational expectations hypothesis equation (1) has the well known forward looking solution that et is the weighted sum of current and expected future market fundamentals. In contrast to this, Frankel and Froot (1986) assumed that portfolio managers generate their exchange rate expectations using a mixture of chartist $E_{t}^{c}\left[\left[\boldsymbol{\Delta}_{\boldsymbol{t}+1}\right]\right] E_{t}^{c}\left[\left[\boldsymbol{\Delta}_{\boldsymbol{t}+1}\right]\right]$ and fundamentalist $E_{t}^{c}\left[\left[\boldsymbol{\Delta} \boldsymbol{e}_{t+1}\right]\right]$ forecasts:

$$
\begin{aligned}
& E_{t}^{c}\left[\left[\boldsymbol{\Delta}_{\boldsymbol{t + 1}}\right]\right]=\omega_{t} E_{t}^{f}\left[\boldsymbol{\Delta} \boldsymbol{e}_{\boldsymbol{t + 1}}\right]+(\mathbf{1}-\boldsymbol{\omega}) E_{t}^{c}\left[\boldsymbol{\Delta} \boldsymbol{e}_{\boldsymbol{t + 1}}\right] \\
& E_{t}^{c}\left[\left[\boldsymbol{\Delta}_{\boldsymbol{t + 1}}\right]\right]=\omega_{t} E_{t}^{f}\left[\boldsymbol{\Delta} \boldsymbol{e}_{\boldsymbol{t + 1}}\right]+(\mathbf{1}-\boldsymbol{\omega}) E_{t}^{c}\left[\boldsymbol{\Delta} \boldsymbol{e}_{\boldsymbol{t + 1}}\right]
\end{aligned}
$$

The parameter $\mathrm{E}_{\mathrm{t}}$, denoting the weight given to fundamentalist views at date $\mathrm{t}$, is dynamically updated by the portfolio managers in a rational Bayesian manner:

$$
\Delta \omega_{t}=\delta\left(\omega_{t-1}^{*}-\omega_{t-1}\right) \Delta \omega_{t}=\delta\left(\omega_{t-1}^{*}-\omega_{t-1}\right)
$$

With :

$$
\omega_{t-1}^{*}=\frac{\Delta e_{t}-E_{t}^{c}\left(\Delta e_{t}\right)}{E_{t-1}^{f}\left[\Delta e_{t}\right]-E_{t-1}^{c}\left[\Delta e_{t}\right]} \omega_{t-1}^{*}=\frac{\Delta e_{t}-E_{t}^{c}\left(\Delta e_{t}\right)}{E_{t-1}^{f}\left[\Delta e_{t}\right]-E_{t-1}^{c}\left[\Delta e_{t}\right]}
$$

Where $\omega_{t-1}^{*} \omega_{t-1}^{*}$ is the expost calculated weight that must have been assigned to fundamentalist forecast in order to predict the current exchange rate change accurately. The value of reflects the extent to which portfolio managers enclose new information in this adaptive process and proves responsible for the exchange rate dynamics. Since portfolio managers always maintain a positive weight for both chartist and fundamentalist forecasts, has to be restricted so that stays in the range between 0 and 1 . To makesure that the empirical analysis remain stractable, another feedback rule is introduced. Similar to Lewis(1989), portfolio managers are supposed to optimize the weight assigned to fundamentalist forecasts by means of a Bayesian learning process: 


$$
\begin{aligned}
\omega_{t} & =\frac{\omega_{t-1} \cdot \varphi_{f}\left(\Delta e_{t} \mid E_{t-1}^{f}\left[\Delta e_{t}\right]\right)}{\omega_{t-1} \cdot \varphi_{f}\left(\Delta e_{t} \mid E_{t-1}^{f}\left[\Delta e_{t}\right]\right)+\omega_{t-1} \cdot \varphi_{c}\left(\Delta e_{t} \mid E_{t-1}^{c}\left[\Delta e_{t}\right]\right)} \\
\omega_{t} & =\frac{\omega_{t-1} \cdot \varphi_{f}\left(\Delta e_{t} \mid E_{t-1}^{f}\left[\Delta e_{t}\right]\right)}{\omega_{t-1} \cdot \varphi_{f}\left(\Delta e_{t} \mid E_{t-1}^{f}\left[\Delta e_{t}\right]\right)+\omega_{t-1} \cdot \varphi_{c}\left(\Delta e_{t} \mid E_{t-1}^{c}\left[\Delta e_{t}\right]\right)}
\end{aligned}
$$

Where

$$
\varphi_{c}\left(\Delta e_{t} \mid E_{t-1}^{c}\left[\Delta e_{t}\right]\right) \varphi_{c}\left(\Delta e_{t} \mid E_{t-1}^{c}\left[\Delta e_{t}\right]\right)
$$$$
\varphi_{f}\left(\Delta e_{t} \mid E_{t-1}^{f}\left[\Delta e_{t}\right]\right) \varphi_{f}\left(\Delta e_{t} \mid E_{t-1}^{f}\left[\Delta e_{t}\right]\right)
$$

density function of $\Delta e_{t} \Delta e_{t}$ conditional on conditional on the forecasts of chartists and fundamentalists, respectively.

\subsection{Fundamentalist Rule}

Concerning the expectation formation fundamentalists have in mind some kind of long-run equilibrium , to which the exchange rate reverts with a given speed over time, i.e.:

$$
E_{t}^{f}\left[\Delta e_{t+1}\right]=\theta\left(\widetilde{e_{t}}-e_{t}\right) E_{t}^{f}\left[\Delta e_{t+1}\right]=\theta\left(\widetilde{e_{t}}-e_{t}\right)
$$

This can be explained by the fact that agents have different beliefs about the equilibrium value of the exchange rate, which is certainly not observable. Kilian and Taylor (2001) conclude that the heterogeneity of beliefs will diminish when the exchange rate becomes increasingly overvalued and the supply of foreign exchange should rise. According to (4) fundamentalist expectation can be viewed as distributed symmetrically around . We assume that the fundamental value can be described by purchasing power parity (PPP) or uncovered interest parity (UIP). PPP states that exchange rates between any two currencies will adjust to reflect changes in the price levels of the two countries. The theory of PPP is simply an application of the law of one price to national price levels rather than to individual price. Takagi (1991) provides evidence from survey data that foreign exchange market participants accept PPP as a valid relationship only in the long run implying low values for . This view is recently supported by Taylor and Peel (2000) and Taylor et al. (2001) showing that due to its nonlinear dynamics the exchange rate reverts to the PPP level, but only in the long run. Furthermore, PPP as a measure of the fundamental exchange rate seems to be suitable for the investigation of central bank intervention, because monetary authorities have used it as a target level (Dominguez and Frankel, 1993b). However, in many cases, the Theory of Purchasing Power Parity cannot fully explain exchange rates. The PPP conclusion that exchange rates are determined solely by changes in relative price levels rests on the assumption that all goods are identical in both countries and that transportation costs and trade barriers are very low. When this assumption is true, the law of one price states that the relative prices of all these goods (that is, the relative price level between the two countries) will determine the exchange rate. PPP theory furthermore does not take into account that many goods and services (whose prices are included in a measure of a country's price level) are not traded across borders. Housing, land, and services such as restaurant meals, haircuts, and golf lessons are not traded goods. So even though the prices of these items might rise and lead to a higher price level relative to another country's, there would be little direct effect on the exchange rate. Therefore, we use uncovered interest parity (UIP) as an approach to long-run exchange rate expectation within fundamentalist rule. Within this framework, central bank operations on foreign exchange markets can be called effective, if the adjustment of the exchange rate to its long run equilibrium is accelerated. This implies that the observed reversion of the exchange rate to uncovered interest parity (UIP) condition - denoted by - is driven by both fundamentalist speculation and central bank intervention. Denoting the influence of intervention by , we can formulate as a function of a 0,1 intervention dummy $I_{t} I_{t}$ as follows:

$$
\zeta_{t}=\theta+\delta_{\theta} I_{t}, \quad \theta, \delta_{\theta}>0
$$

\subsection{Chartist Rule}

Chartists are defined as market participants who believe that exchange rate time series exhibit regularities which can be detected by a wide range of so-called technical trading rules. To reduce the impact of data snooping biases brought on by searching for the best performer, we employ a very simple type of trading rule following common practice (Takagi,1991). Excess returns of moving average (MA) trading rules of daily U.S. dollar quotes for the DM, yen, poundsterling and swiss francis reported in Neely(1997) and LeBaron (1999). Leeetal (2001) found MA trading rule profitability for Latin American currencies applying out of sample-tests. These studies show that the length of the short run and long run moving average don't have much influence on the trading rule profitability. To be concrete, chartists are supposed to expect that a future exchange rate increase is predicted by the proportion of the positive difference between the 14 day moving average $\left(\mathrm{ma}_{14}\right)$ and 200 day moving average $\left(\mathrm{ma}_{200}\right)$ and vice versa. Hence, their exchange rate expectation at date $\mathrm{t}$ is: 


$$
E_{t}^{c}\left[\Delta e_{t+1}\right]=\psi\left(m a_{14, t}-m a_{200, t}\right) E_{t}^{c}\left[\Delta e_{t+1}\right]=\psi\left(m a_{14, t}-m a_{200, t}\right)
$$

As is stated in the noise trader hypothesis of intervention (Hung,1997), a leaning against the wind-strategy of central banks may introduce trends into exchange rate dynamics. Subsequent changes in noise trader's positions magnify the initial impact of intervention operations. We assume that this kind of trend establishing intervention can be formalized by means of a moving average specification very similar to speculation based on chartist analysis. This implies that a given trend in the exchange rate () is due to both chartist speculation and central bank intervention. Denoting the influence of intervention by, we can formulate as a function of the intervention dummy It as follows:

$$
\eta_{t}=\psi+\delta_{\psi} I_{t} \quad \psi, \delta_{\psi}>0
$$

Of course, neither the chartists, the fundamentalists, nor the portfolio managers have rational expectations about the future exchange rates. Within the model, agents could do a better job in expected value terms, if they knew the complete model. But as long as market participants try to compensate the lack of a verified exchange rate model with different forecasting techniques, the imposed informational restrictions are a realistic description of the foreign exchange market.

In order to confront the C\&F-model with exchange rate data, the econometric approach should be able to describe the conditional distribution of the exchange rate change by a mixture of (normal) distributions. As is stated in Clarida et al.(2001) the Markov regime- switching model suggested by Engel and Hamilton (1990) and developed further by, among others, Engel (1994), Vigfusson (1997) and Dewachter (2001) is a natural candidate to characterize exchange rate behavior. In our model, the conditional mean $t$ and the conditional variance ht of exchange rate changes et are allowed to follow two different regimes-a chartist and a fundamentalist regimeindicated by an unobservable state variable St. The regime indicator St is parameterized as a first-order Markov process and the switching or transition probabilities $\mathrm{P}$ and $\mathrm{Q}$ have the typical Markov structure:

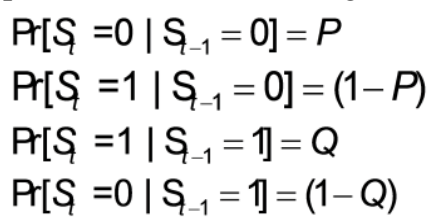

Thus, under conditional normality, an observed realization $\Delta e_{t} \Delta e_{t}$ is presumed to be drawn from a $\mathrm{N}\left(\mu_{0 \mathrm{t}}, \mathrm{h}_{0 \mathrm{t}}\right)$ distribution if $\mathrm{S}_{\mathrm{t}}=0$, whereas $\Delta e_{t} \Delta e_{t}$ is distributed $\mathrm{N}\left(\mu_{1 \mathrm{t}}, \mathrm{h}_{1 \mathrm{t}}\right)$ The evolution of the log first differences of exchange rates can therefore be written as:

$$
\begin{gathered}
\Delta e_{t}=\mu_{0 t}\left(1-S_{t}\right)+\mu_{1 t} S_{t}+\sqrt{h_{0 t}\left(1-S_{t}\right)+h_{1 t} S_{t}} \\
\Delta e_{t}=\mu_{0 t}\left(1-S_{t}\right)+\mu_{1 t} S_{t}+\sqrt{h_{0 t}\left(1-S_{t}\right)+h_{1 t} S_{t}} . \varepsilon_{\mathrm{t}}
\end{gathered}
$$

Where $t$ is an i.i.d. standard normal variable. The parameter estimation of the mean (t) and variance (ht) equation since the regime switching model are derived from maximization of the log-likelihood function

$$
\begin{gathered}
L=\log p_{1 t} \frac{1}{\sqrt{2 \pi h_{1 t}}} \exp \frac{-\left(\Delta e_{t}-\mu_{1 t}\right.}{2 h_{1 t}}+\left(1-p_{1 t}\right) \frac{1}{\sqrt{2 \pi h_{2 t}}} \exp \frac{-\left(\Delta e_{t}-\mu_{1 t}\right.}{2 h_{2 t}} \\
L=\log p_{1 t} \frac{1}{\sqrt{2 \pi h_{1 t}}} \exp \frac{-\left(\Delta e_{t}-\mu_{1 t}\right.}{2 h_{1 t}}+\left(1-p_{1 t}\right) \frac{1}{\sqrt{2 \pi h_{2 t}}} \exp \frac{-\left(\Delta e_{t}-\mu_{1 t}\right.}{2 h_{2 t}}
\end{gathered}
$$

$p_{1 t} p_{1 t}=\operatorname{Pr}\left(\mathrm{S}_{\mathrm{t}}=1 \mid \Phi_{\mathrm{t}-1}\right)$ is the probability that the analyzed process is in regime 1 at time $\mathrm{t}$ and is updated by means of Bayesian inference using information available at time $t-1$. Therefore, $p_{1 t}$ and $\left(1-p_{1 t}\right)$ can be regarded as weights assigned to regime dependent forecasts resulting from a rational learning process as outlined in the theoretical exchange rate model. For comparison purposes, we first specify the mean equations without taking into account foreign exchange market activities of central banks. However, the important results of the study are derived from mean equations that include intervention dummies as it is done in the second specification.

(1)The standard regime-switching-c\&f model: $R S-C F$

The mean equation of the first regime represent the fundamentalist regime including the deviation of the exchange rate from its fundamental value $e_{t}$ describe by Uncovered Interest Parity (UIP) as outlined above. The second regime's mean equation contains chartist expectation, i.e the moving average trading consisting of the differences between $\mathrm{ma}_{14}$ and $\mathrm{ma}_{200}$ :

$$
\mu_{0 t}=\theta\left(p p p_{t-1}-e_{t-1}\right.
$$




$$
\mu_{1 t}=\psi\left(m a_{14, t-1}-m a_{200, t-1}\right)
$$

The variance of et,i.e.the volatility of $\mathrm{e}_{\mathrm{t}}$ is assumed to be constant within regimes, $\mathrm{h}_{0 \mathrm{t}}=\sigma_{F}^{2} \sigma_{F}^{2}$ and $\mathrm{h}_{1 \mathrm{t}}=\sigma_{c}^{2}$ $\sigma_{c}^{2}$ so that the only source of conditional heteroscedasticity is the regime switching behavior.

\section{(2)The intervention augmented regime-switching-c\&f model: RS-CF-Int}

To introduce intervention operations into the regime-switching framework, we define that the dummy variable It $=1$, if the central bank intervenes at time $t$ and $\mathrm{It}=0$, otherwise and rewrite the mean equations of the standard C\&F model as follows:

Fundamentalist Rule without FX intervention Specification

\section{With FX intervention}

\section{Chartist Rule without intervention Specification}

\section{With FX Intervention}

As long as interventions do not occur, i.e. It $=0$, this more general formulation boils down to the standard RSCF model. More interestingly, if the foreign exchange intervention of the central bank had an impact on the forecasting performance of chartists and fundamentalists, a change of coefficients represented by significant estimates of the various s should be observed. By introducing intervention dummies in the specification of second Moments $\mathrm{h}_{0 \mathrm{t}}={ }_{F}^{2}+\delta_{\sigma_{F}^{2}} \sigma_{F}^{2}+\delta_{\sigma_{F}^{2}} . \mathrm{I}_{\mathrm{t}}$ and $\mathrm{h}_{1 \mathrm{t}}=\sigma_{c}^{2}+\delta_{\sigma_{c}^{2}} \sigma_{c}^{2}+\delta_{\sigma_{c}^{2} \text {. It }}$ we are able to re-examine the relationship between central bank intervention and exchange rate volatility, where the existing literature provided mixed evidence (Baillie and Osterberg, 1997b and Dominguez, 1998).

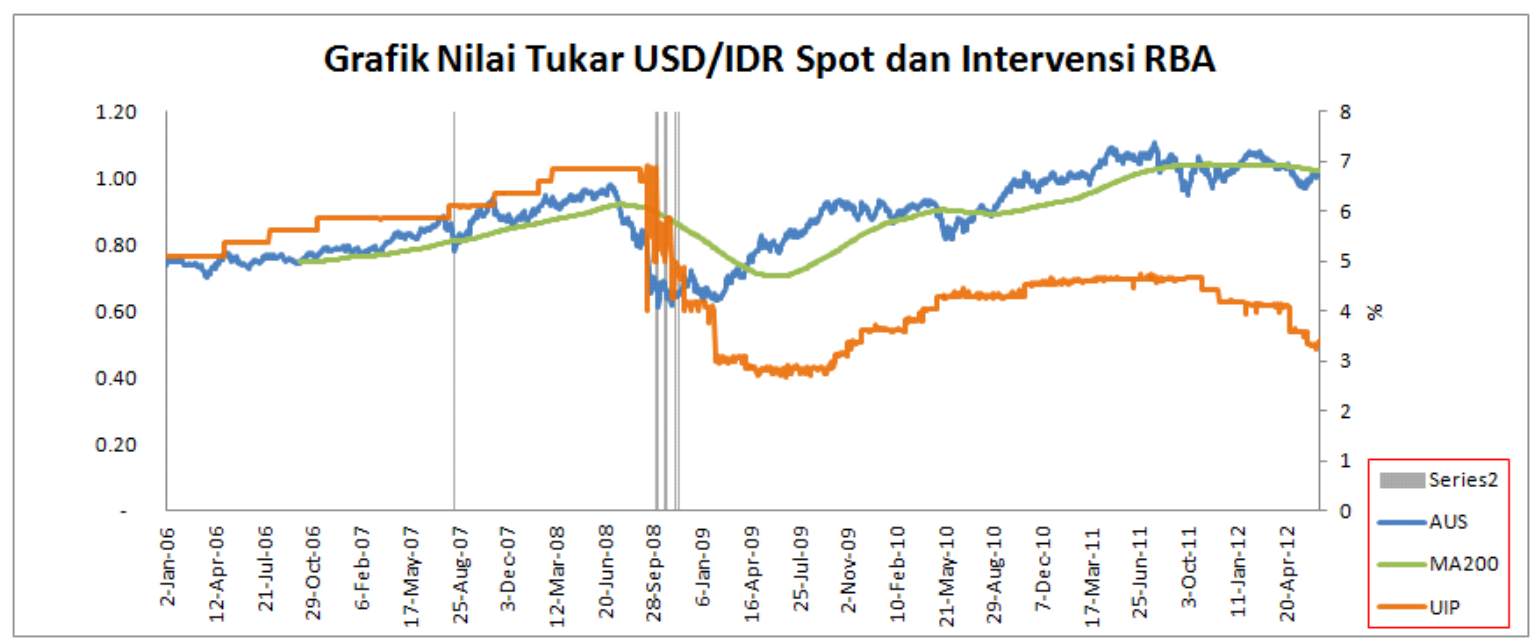

Figure 1. AUD/USD Spot, UIP, MA200 \& the RBA Intervention

\section{Empirical Results}

The models described above were estimated by maximum likelihood. Parameter estimates were obtained using the BFGS algorithm, and the reported t-statistics are based on heteroskedastic-consistent standard errors (White,1982). The estimates are derived from the daily AUD/US-Dollar spot exchange rate series kindly supplied by the RBA. The UIP was constructed using daily O/N Interbank rate of AUD and USD. The intervention dummy series is based on intervention data from the RBA. The foreign exchange intervention series only includes active trades made by the RBA for reasons of influencing foreign exchange rates. Purchases and sales of the RBA are reported whenever they changed their net foreign assets. The sample extends from January 2006 to June 2012. The series of the spot exchange rate, the UIP relation and the 200 day moving average are presented in upper graph, the RBA purchases and sales of Dollars against AUD can be found in the middle graph.

Table 1 contains the estimates of both the RS-CF, and the RS-CF-Int models for Australian Case. As regards the transition probabilities, the models differ slightly at best. P and Q range above 0.95 thereby indicating high persistence of regimes. The unconditional probability of the fundamentalist regimes $\mathrm{P}$ is lower $(0.4)$ than the one assigned to chartist regimes (0.6). This is also reflected in the expected duration of regimes. The (first) fundamentalist regimes are expected to last up to 21 trading days whereas the (second) chartist regimes have a longer duration of at least 32 trading days. Significant estimates of variances point to regime dependent heteroskedasticity capturing periods of high and low volatility: The second moment in the second regimes is 
lower than the variance in the first regimes. The estimates of chartist and fundamentalist coefficients and are statistically significant and of the correct sign

\begin{tabular}{|c|c|c|}
\hline & RS-CF & RS-CF-Int \\
\hline$\theta$ & $\begin{array}{l}0,257 \\
(11,74) * * *\end{array}$ & $\begin{array}{l}0,251 \\
(13,02) * * *\end{array}$ \\
\hline$\delta_{\theta}$ & & $\begin{array}{l}0,156 \\
(2,86) * * *\end{array}$ \\
\hline$\omega_{\theta}$ & & \\
\hline$\psi$ & $\begin{array}{l}0,081 \\
(10,68) * * *\end{array}$ & $\begin{array}{l}0,080 \\
(12,90)^{* * *}\end{array}$ \\
\hline $\begin{array}{c}\delta_{\psi} \\
\omega_{\theta}\end{array}$ & & $\begin{array}{l}0,011 \\
(0,16)\end{array}$ \\
\hline$\sigma_{F}^{2}$ & $\begin{array}{l}8,37 \times 10^{-5} \\
(6,33) * * *\end{array}$ & $\begin{array}{l}8,19 \times 10^{-5} \\
(6,41)^{* * * *}\end{array}$ \\
\hline$\delta_{\sigma_{F}^{2}}$ & & $\begin{array}{l}0,43 \times 10^{-5} \\
(0,10)^{*}\end{array}$ \\
\hline$\sigma_{C}^{2}$ & $\begin{array}{l}1,74 \times 10^{-5} \\
(6,04) * * *\end{array}$ & $\begin{array}{l}1,71 \times 10^{-5} \\
(7,75)^{* * * *}\end{array}$ \\
\hline$\delta_{\sigma_{C}^{2}}$ & & $\begin{array}{l}0,80 \times 10^{-6} \\
(0,1)\end{array}$ \\
\hline $\mathrm{P}$ & $\begin{array}{l}0,953 \\
(33,55) * * *\end{array}$ & $\begin{array}{l}0,954 \\
(42,34) * * *\end{array}$ \\
\hline Q & $\begin{array}{l}0,969 \\
(47,05)^{* * *}\end{array}$ & $\begin{array}{l}0,969 \\
(54,39) * * *\end{array}$ \\
\hline $\bar{P}$ & 0,398 & 0,406 \\
\hline $\bar{Q}$ & 0,602 & 0,594 \\
\hline$(1-P)^{-1}$ & 21,48 & 21,81 \\
\hline$(1-Q)^{-1}$ & 32,54 & 31,94 \\
\hline Log-Likelihood & 5266,31 & 5270,10 \\
\hline LRT & & $7,59 *$ \\
\hline
\end{tabular}

Table 1.Estimation Result

\section{Conclusion}

Although there is evidence that monetary authorities tried to avoid misalignments and counter 'disorderly markets', the impact of central bank intervention on foreign exchange rates repeatedly turned out to be low when assessed by means of conventional single regime approaches. It becomes even more difficult to imagine a rational expectations model capable of explaining these results, when taking into account that intervention seems to increase the profitability of technical trading rules (LeBaron,1999). On the basis of the theoretical heterogeneous expectation framework, a generalization of Hung's (1997) noise trading channel is estimated by means of an intervention augmented two state Markov regime-switching model. We show that the predictive power of sophisticated fundamentalist forecasting techniques approximated by the deviation of the current exchange rate from the UIP level, was enhanced whenever the RBA intervened on the foreign exchange market, whereas simple chartist approach was not strengthened in these periods. However, intervention seems to have small influence on the weight assigned to either forecasting strategy.

If chartist analysis tends to be destabilizing as is widely accepted in the literature, a volatility enhancing impact of central bank intervention on exchange rates, can not be ruled out. However, this is little proof by the finding that the intervention dummy identified periods in which the volatility is a bit increasing especially within fundamentalist rule. Of course, we have to address a serious causality problem. Before quickly concluding that exchange rate volatility is due to intervention operations, 'disorderly markets', i.e. high volatility, may have challenged central bank activities. But as long as this reverse causality is not confirmed, central bank intervention remains an ambiguous policy tool in influencing exchange rates.

\section{References}

- $\quad$ Ahrens et.al, 2003."Heterogeneous Expectations in the Foreign Exchange Market Evidence from the Daily Dollar/DM Exchange Rate”.CFS Working Paper No. 2003/11.German. 
- Baillie, R and Osterberg, W, 1997a."Central Bank Intervention and Risk in the ForwardMarket”, Journal of International Economics, Vol. 43, p.483 - 497.

- $\quad$ Baillie, R and Osterberg, W, 1997b.“Why Do Central Banks Intervene?”,Journal of International Money and Finance, Vol. 16, p. $909-919$.

- Ben Maatoug, et.al, 2010. “Central Bank Intervention within a Chartist-Fundamentalist Exchange Rate Model: Evidence from the RBA Case".

- Clarida et al, 2001."The Out-of-Sample Success of Term Structure Models as Exchange Rate Predictors: A Step Beyond", Mimeo.

- Dewachter, H, 2001.“Can Markov Switching Models Replicate Chartist Profits in the Foreign Exchange Market?”,Journal of International Money and Finance, Vol. 20, p.25-41.

- Dominguez and Kathryn M, 1998.“Central Bank Intervention and Exchange Rate Volatility”.Journal of International Money and Finance, 17(1998) 161-190. USA.

- Engel, Ch, 1994.“Can the Markov Switching Model forecast Exchange Rates?”,Journal of International Economics, Vol. 36, p.151 - 165.

- Engel, Ch and Hamilton, J, 1990.“Long swings in the Dollar: Are they in the data and do markets know it?”,American Economic Review Vol. 80, p.689 - 713.

- Frankel, J.A. andFroot, K.A, 1986, "Understanding the US Dollar in the Eighties: The Expectations of Chartists and Fundamentalists", The Economic Record, 24 - 38.

- $\quad$ Frankel, J.A. and Froot, K.A, 1989. "Chartists, Fundamentalists, and Trading in the Foreign Exchange Market", American Economic Review Papers and Proceedings, vol.80, p.181-5

- Hung, J, 1997.“Intervention Strategies and Exchange Rate Volatility: A Noise Trading Perspective”, Journal of International Money and Finance, Vol. 16, p. 779 - 793.

- $\quad$ Krugman and Paul R, 2000. "Technology, trade and factor prices," Journal of International Economics, Elsevier, vol. 50(1), pages 51-71.

- LeBaron, B, 1999.“Technical Trading Rule Profitability and Foreign Exchange Intervention”, Journal of International Economics, Vol. 49, p.125 - 143.

- Lee, Ch et al, 2001. "Trading rule profits in Latin American currency spot rates", International Review of Fin. Analysis, Vol. 10, p.135 - 156.

- Ma, Guonan et al, 2004.’The Markets for non-deliverable forwards in Asian Currencies”, BIS Quarterly Review

- Neely, C, 1997. “Technical Analysis in the Foreign Exchange Market: A Layman's Guide”, Federal Reserve. Bank of St. Louis Review, Vol. 79:5,p. 23 - 38.

- Neely, C and veller, P, 2001.'Technical Analysis and Central Bank Intervention”, Journal of International Money and Finance, Vol. 20, p.949 - 970.

- Pilbeam K, 1998. "International Finance” $2^{\text {nd }}$ Edition.Palgrave Publishers Ltd. New York, USA.

- $\quad$ Reitz, S, 2002. "Central Bank Intervention and Exchange Rate Expectations - Evidence from the Daily DM/US-Dollar Exchange Rate". Discussion Paper 17/02. Economic Research Centre of the Deutsche Bundesbank.

- $\quad$ Richard TB and William PO, 1998."Central bank intervention and overnight uncovered interest rate parity," Working Paper 9823, Federal Reserve Bank of Cleveland.

- $\quad$ Röthig, et.al ,2005. "Corporate Currency Hedging and Currency Crises," Publications of Darmstadt Technical University, Institute of Economics (VWL) 27194, Darmstadt Technical University, Department of Business Administration, Economics and Law, Institute of Economics (VWL).

- Takagi, S, 1991. "Exchange Rate Expectations, A Survey of Survey Studies”, IMF Staff Papers, Vol. 38 (1)

- Taylor, MP, 2004. “Is Official Exchange Rate Intervention Effective?”.Economica, 71,1-11. The London School of Economics and Political Science.

- Vigfusson, R, 1996. "Switching Between Chartists and Fundamentalists: A Markov RegimeSwitchingApproach”. Working Paper 96-1. Bank of Canada.

- Wang, P, 2009. “The Economics of Foreign Exchange and Global Finance”,Springer-Verlag Berlin Heidelberg

- White, H,1982."Maximum likelihood estimation of misspecified models”, Econometrica, Vol. 50,p. 1 - 25.

- Warjiyo, P, 2004. “Ekonomi KeuanganInternasional: Teori, Model Empiris, dan Kebijakan”. Program Pascasarjana - Universitas Indonesia Program Studi Ilmu Ekonomi. 